\title{
Analisis Return on Investment (ROI) dengan Penelusuran Basis Data Guna Perhitungan Tingkat Keberhasilan Promo
}

\author{
Return on Investment (ROI) Analysis with Database Searching \\ to Calculate the Success Rate of the Promo
}

\author{
Akrilvalerat D W*1, Joni Saputra ${ }^{2}$, Irfan Purwanto ${ }^{3}$, M. Afriansyah ${ }^{4}$, \\ Nur Fitrianingsih Hasan ${ }^{5}$, Vera Wati ${ }^{6}$, Lukmanul Hakim ${ }^{7}$ \\ 1,2,3,4,6,7 Magister Teknik Informatika Universitas AMIKOM Yogyakarta, \\ ${ }^{5}$ STIMIK Sepuluh Nopember Jayapura \\ E-mail: *1akrilvha8@gmail.com, ${ }^{2}$ saputrajoni798@gmail.com, \\ 3irfanpurwanto@gmail.com, ${ }^{4}$ afriansyah40@gmail.com, ${ }^{5}$ fitriahasan.papuan@gmail.com, \\ ${ }^{6}$ verave.wati@gmail.com, ${ }^{7}$ lukmanulhakim@gmail.com
}

\begin{abstract}
Abstrak
Perusahaan Planet Host adalah perusahaan penyedia layanan pembelian domain dan web hosting untuk menyimpan data website yang dibutuhkan konsumen. Selayaknya perusahaan lain, strategi pemasaran melalui promosi menjadi salah satu hal yang harus dilakukan perusahaan untuk menyediakan penawaran produk yang menarik konsumen dengan tujuan konsumen akan berlangganan secara terus-menerus. Strategi promosi dilakukan pihak perusahaan agar tepat sasaran, sehingga tujuan perusahaan tercapai. Biaya modal pemasaran yang cepat kembali menjadi salah satu tujuan perusahaan. Tingkat kesuksesan dalam kegiatan pemasaran menerapkan perhitungan menggunakan ROI (Return on Investment). Hasil perhitungan ini dibantu penelusuran melalui database untuk mengetahui hasil profitable dari ROI untuk membantu pengambil keputusan mengukur efektivitas dari keseluruhan operasi perusahaan. Hasil dari penelitian setelah penelusuran query basis data dengan View, Store Procedure, Trigger, analisa ROI penjualan produk pada kode promo Harbolnas total pembelian 12 produk, Black Friday total pembelian 23 produk dan total pembelian nonpromo 12 produk. Namun, kode promo Harbolnas lebih signifikan dalam memperoleh laba yaitu 54\% selama periode November-Desember, dibanding dengan promo Black Friday yaitu 51,75\%.
\end{abstract}

Kata Kunci - web hosting, domain, strategi promosi, basis data, ROI

Planet Host company is a company that provides domain and web hosting services to store website data needed by consumers. Like other companies, a marketing strategy through promotion is one of the things that companies must do to provide product offerings that attract consumers with the aim of consumers going to subscribe continuously. Promotion strategies are carried out by the company to be right on target, so that the company's goals are achieved. The cost of marketing capital is fast becoming one of the company's goals. The level of success in marketing activities applies calculations using ROI (Return on Investment). The results of this calculation are assisted by searching through the database to find out the profitable results of ROI to help decision makers measure the effectiveness of the company's overall operations. Results from research after searching database queries with View, Store Procedure, Triggers, analysis of product sales ROI on Harbolnas promo codes total purchases of 12 products, Black Friday total purchases of 23 products and total purchases of 12 nonpromo products. However, Harbolnas promo code is more significant in gaining profit, which is $54 \%$ during the NovemberDecember period, compared to the Black Friday promo, which is $51.75 \%$.

Keywords - web hosting, domain, promotion strategy, database, ROI 


\section{PENDAHULUAN}

Perubahan yang terjadi akibat era revolusi insdustri 4.0 yang berdampak pada penjualan produk dengan memanfaatkan teknologi, berupa digital economy, artificial intelligence, big data, dan robotic menjadi salah satu pemicu terjadinya transformasi perilaku konsumsi dan menyebabkan perubahan pola penjualan dan promosi yang berubah. Pembeli dan penjual tidak dibatasi ruang dan waktu dalam melakukan transaksi. Beberapa strategi promosi dilakukan perusahaan agar produk yang ditawarkan menarik bagi konsumen agar mengkonsumsinya secara berulang. Berbagai media dan strategi promosi dipilih oleh para pelaku usaha agar tepat sasaran dan target, sehingga tujuan perusahaan tercapai dan tentunya modal yang di keluarkan kembali [1].

Strategi promosi adalah salah satu cara yang bisa digunakan untuk meningkatkan citra perusahaan. Salah satu faktor yang menentukan tingkat keberhasilan adalah kemampuan perusahaan dalam memberikan kualitas pelayanan kepada konsumen [2]. Meningkatkan citra perusahaan berkaitan erat dengan kegiatan pemasaran, semakin cepat kembalinya semua biaya modal untuk kegiatan pemasaran (investasi) maka semakin baik. Tentu perusahaan menginginkan untuk mendapatkan return dari semua biaya pengeluaran yang dilakukan, untuk itu perusahaan harus mampu menghitung hasil dari suatu kegiatan pemasaran salah satu metode yang dapat digunakan yaitu dengan perhitungan Return On Invesment atau ROI [3].

Mengacu pada penelitian terdahulu [4], dengan judul penelitian "Pengaruh Return On Investment (ROI) dan Corporate Social Responibility (CSR) Terhadap Nilai Perusahaan dengan Profitabilitas sebagai Variabel Moderating" dimana telah melakukan penelitian terhadap analisis ROI (Return On Investment). Rasio atas jumlah aktiva (return) ini digunakan untuk mengukur efektivitas dari keseluruhan operasi perusahaan. Faktor yang dapat mempengaruhi ROI diantaranya Turnover dari operating assets dan profit margin. Penelitian lain [4] menghasilkan kesimpulan variable ROI dan CSR berpengaruh signifikan terhadap nilai perusahaan, variabel profitabilitas berpengaruh terhadap hubungan antara ROI dengan nilai perusahaan dengan perhitungan rumus ilmu ekonomi khususnya akuntansi. Berbeda dengan penelitian yang dilakukan [5] dengan memaksimalkan laba atas investasi ROI dari proyek restorasi untuk mendukung kepentingan keanekaragaman hayati dan jasa ekosistem yang mendukung kesejahteraan manusia.

Selain itu, penelitian menjelaskan bahwa penggunaan teknologi pada sebuah perusahaan memiliki peran yang sangat penting di era big data ini [6]. Salah satu teknologi yang harus dimiliki oleh sebuah perusahaan adalah teknologi dalam memproses data sehingga menjadi informasi yang berguna, yaitu pengolahan basis data. Literatur lain [7] telah memanfaatkan basis data sebagai teknologi informasi yang tepat, yang sangat membantu dalam mengambil keputusan manajerial di Perpustakaan Sekolah. Penggunaannya pada perusahaan mampu membantu seorang admin ketika melakukan pencarian data dan membantu manajer dalam mengambil keputusan. Pengolahan data tersebut dilakukan dengan query-query pada basis data dengan basis data manajemen sistem [8]. Basis data merupakan sekumpulan file yang saling berhubungan dan terorganisir atas kumpulan record-record yang menyimpan data dan hubungan diantaranya data yang penting dan terintegrasi dan diatur sedemikian rupa sehingga data dapat dimanipulasi, diambil dan dicari secara cepat [9].

Berdasarkan rujukan literatur terdahulu, penelitian ini akan diarahkan dengan melibatkan basis data menggunakan beberapa fungsi penulusuran query menggunakan View, Trigger, Store Proscedure serta penelusuran query yang mendukung dalam menganalisa perhitungan Return On Investment (ROI) guna mengetahui tingkat keberhasilan promo dan informasi keterkaitan konsumen dalam penggunaan kode promo tertentu. ROI memberikan pengetahuan untuk mengetahui kapan akan menginvestasi lebih atau bahkan mengurangi investasi. ROI memperlihatkan tingkat kesuksesan dari kegiatan pemasaran yang dilakukan dan akan membawa perusahaan lebih sukses yang nantinya akan dapat merubah keuangan perusahaan menjadi lebih baik [4]. Studi kasus yang dianalisa adalah perusahaan Planet Host penyedia layanan web hosting dan domain. Tujuan penggunaan ROI ini hasilnya sebagai mengukur profitabilitas dari masing- 
masing produk yang dihasilkan Perusahaan Planet Host, selain itu berguna untuk controlling dan planning dalam pengambilan keputusan. Sehingga promo tersebut dapat menjadi pertimbangan untuk diimplementasikan kembali pada periode selanjutnya berdasarkan tingkat keberhasilan.

\section{METODE PENELITIAN}

Penelitian dilakukan dengan mengumpulkan beberapa studi literasi terkait penelitian dan data yang akan digunakan untuk tahap penulusuran kemudian dilakukan pembuatan basis data dan merancang relasi tabel. Alur dalam pengumpulan data dan penulusuran dapat dilihat pada Gambar 1.

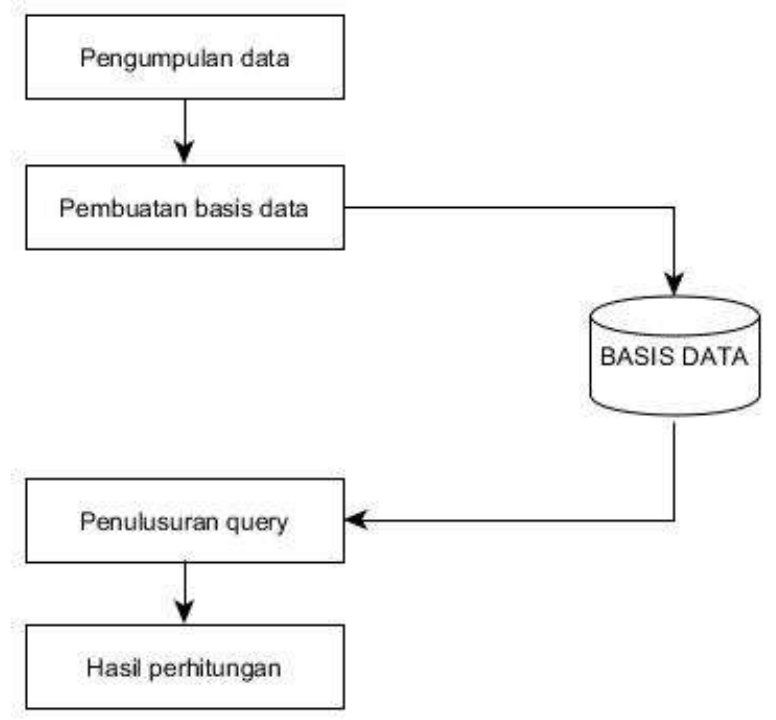

Gambar 1. Alur Pengumpulan Data

Tahap studi literasi dilakukan dengan review pada peneliti terdahulu terkait strategi perancangan serta pengelolaan basis data dan analisis perhitungan ROI pada penelitian bidang ekonomi maupun akuntansi. Data yang dikumpulkan data pembelian produk hosting, domain secara periodik yaitu dari bulan November-Desember.

Basis data adalah kumpulan data yang saling berelasi. Data sendiri merupakan fakta mengenai obyek, orang dan lain-lain. Data dinyatakan dengan nilai (angka, deretan karakter atau symbol). Basis data bertujuan untuk mengatur data sehingga diperoleh kemudahan, ketepatan dan kecepatan dalam pengambilan kembali [10]. ROI adalah kegiatan untuk mengukur keberhasilan kinerja pemasaran yang bertujuan untuk kegiatan pemasaran yang harus dikeluarkan secara optimal tanpa menyebabkan kerugian bagi perusahaan [8]. Model untuk meningkatkan marketing ROI adalah menggunakan marketing value transformation model. Transformasi nilai pemasaran dilakuan dengan cara (1) meningkatkan efektivitas (top line) dan (2) meningkatkan efesiensi (bottom line). Meningkatkan efektifitas dapat dicapai dengan meningkatkan revenue dan profit margin [11].

Studi kasus pada perusahaan Planet Host sebagai penyedia layanan web hosting dan domain. Hosting merupakan jasa layanan internet yang menyediakan server-server untuk untuk disewakan sehigga memungkinkan organisasi atau individu menempatkan informasi di internet merupakan perngertian hosting [12]. Kapasitas hosting cukup beragam, hal ini melihat kebutuhan storage basis data pada web sistem pelanggan online. Sedangkan, untuk mengakses sebuah website membutuhkan identitas yaitu domain, yang biasanya memiliki nama yang unik diberikan untuk mengidentifikasi nama server komputer seperti web server atau server di jaringan komputer [13]. 
Tahap selanjutnya yaitu pembuatan basis data beserta relasi yang kemudian disimpan ke dalam basis data (database) perusahaan domain dan hosting. Penulusuran query dilakukan didalam basis data dengan menggunakan perintah select, lalu membuat fungsi View, Store Procedure dan Trigger. View adalah sebuah virtual tabel yang isi / nilai didalamya di definisikan melalui perintah query (SQL). View terdiri sekumpulan kolom-kolom yang memiliki nama dan baris-baris data, kolom dan baris data ini berasal dari tabel-tabel referensi dalam query yang mendefinisikan view dan dibuat secara dinamis ketika View direferensikan [14]. Suatu nilai attribute sebelum dan sesudah update bisa direferensikan dengan fungsi Trigger, hal ini bisa memanfaatkan Trigger event perintah insert, delete atau update. Trigger ditugaskan untuk mencatat tindakan yang harus dilakukan dalam tabel terpisah, mempertahankan summary data, mereplikasi basis data dengan mencatat perubahan pada relasi spesial [15]. Store Procedure adalah program yang dapat dipanggil oleh aplikasi dengan SQL CALL statement. Prosedur yang disimpan dapat dipanggil secara lokal atau jarak jauh [16].

$$
\mathrm{ROI}=\frac{\text { Gross Margin }- \text { Market Investment }}{\text { Marketing Investment }} \times 100 \%
$$

Penjelasan persamaan ke-1 [17] gross margin mencerminkan NPV (Net Present Value) dari profit pemasaran yang dikurangi perkiraan pengeluaran biaya (Market Investment), kemudian hasilnya di bagi Market Investment hingga dijadikan dalam bentuk nilai persen.

Pada penelitian ini yaitu menggunakan perhitungan penggunaan rumus (2) dan (3) [18]. Net Present Profit mewakili nilai laba bersih sekarang dikurangi anggaran, dimana nilai tersebut menjadi nilai laba bersih pengembalian seutuhnya yang nantinya bagi anggaran dan dijadikan nilai persen untuk mengetahui tingkat keberhasilan dalam persen [19].

$$
\begin{aligned}
& \mathrm{ROI}=\text { Net Present Profit }- \text { Budget }=(\text { Net Return Value }) \\
& \mathrm{ROI}=\frac{\text { Net Return Value }}{\text { Cost of Investment }(\text { Budget })} \times 100 \%
\end{aligned}
$$

\section{HASIL DAN PEMBAHASAN}

\subsection{Pengumpulan dan Analisis Data}

Pengolahan data pertama kali dilakukan dengan pencarian promosi berdasarkan periode, maka hasil periode yang didapatkan data di lakukan pengelompokan berdasarkan kategori kode promo yaitu promo Hari Belanja Online Nasional (Harbolnas) 50\%, promo Black Friday $75 \%$ dan non-promo. Alur pengolahan data dapat dilihat pada Gambar 2.

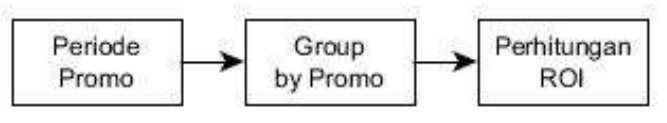

Gambar 2. Alur Pengolahan Data Pencarian Promo

Setelah didapatkan data berdasarkan periodik promo maka dilakukan perhitungan ROI yang mengacu pada persamaan ke-2, seperti ditunjukkan pada Tabel 1. 
Tabel 1. Analisa Promo Perhitungan ROI

\begin{tabular}{|l|c|c|c|c|c|}
\hline Promosi & Budget & $\begin{array}{c}\text { NPV Profit } \\
\text { (Revenue) }\end{array}$ & $\begin{array}{c}\text { Net } \\
\text { Return }\end{array}$ & ROI & $\begin{array}{c}\text { Jumlah } \\
\text { Pembelian }\end{array}$ \\
\hline Promosi Harbolnas (50\%) & 13.700 & 16.400 & 2.700 & $20 \%$ & 112 \\
\hline Promosi Black Friday (75\%) & 11.000 & 14.000 & 3000 & $27 \%$ & 250 \\
\hline Non Promo & 11.200 & 14.000 & 2.800 & $25 \%$ & 45 \\
\hline
\end{tabular}

Net Return dihitung dengan rumus persamaan ke-4 :

$$
\text { NPV Profit - budget }
$$

Pada studi kasus tersedia data sebagai berikut, budget yang dikeluarkan untuk promosi Black Friday adalah sebesar Rp. 11.000, Net profit dari kegiatan promosi adalah sebesar Rp. 3000. Maka, penerapan pada rumus (1) didapatkan hasil ROI dari promosi Black Friday adalah sebesar

$$
\mathrm{ROI}=\frac{R p .3000}{R p .11 .000} \times 100 \%=27 \%
$$

\subsection{Perancangan BasisData}

Pembuatan basis data yang mengacu pengumpulan data yang didapat, maka skema basis data yang di dapat bisa dilihat pada Gambar 3, Gambar 4, Gambar 5, dan Gambar 6.

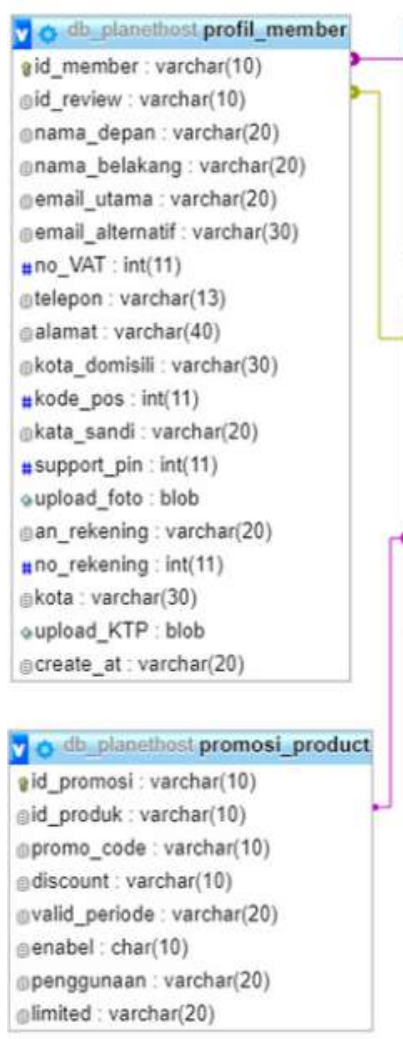

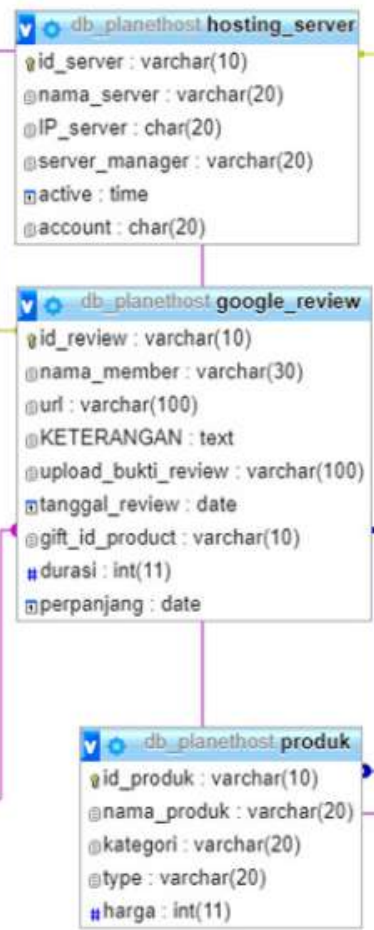

Yo db planethost pesan gid_pesan : varchar $(10)$

einvoice_number : varchar(20) ecurrency : varchar $(20)$

eafiliate_by : varchar(20) oid_member : varchar(10) oid_produk : varchar(10) onama_order : varchar $(20)$ Charga_order : varchar $(20)$

ocode_unik : varchar(20)

epayment_amount : varchar(20) ฐdurasi : time

eorder_status : varchar(20)

oregistrar_status : varchar $(20)$

eorder_create_at : varchar $(20)$

oorder active at : varchar (20)

oorder_expired_at : varchar(20)

(9) order_notes : varchar $(20)$

ostaff_notes : varchar(20)

eorder_group : varchar(20)

\section{o db_planethost detail_hosting}

a id_hosting : varchar(10)

eid_server : varchar(10)

oid_order : varchar $(20)$

epanel : varchar $(50)$

Dspamexpert: varchar $(10)$

edaily_bacup : varchar(20)

domain_relted : varchar(20)

Gambar 3. Skema Basis Data Google Review 
Citec Journal, Vol. 5, No. 3, Mei 2018 - Juli 2018

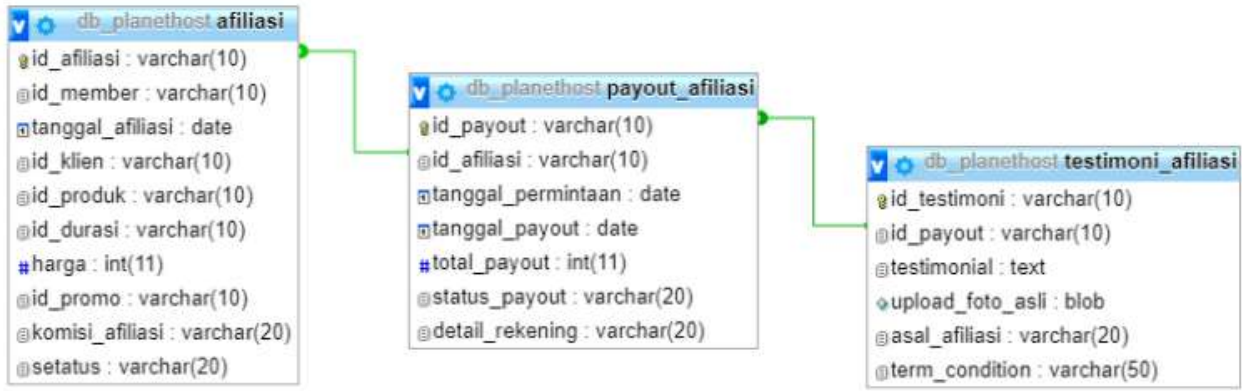

Gambar 4. Skema Basis Data Afiliasi

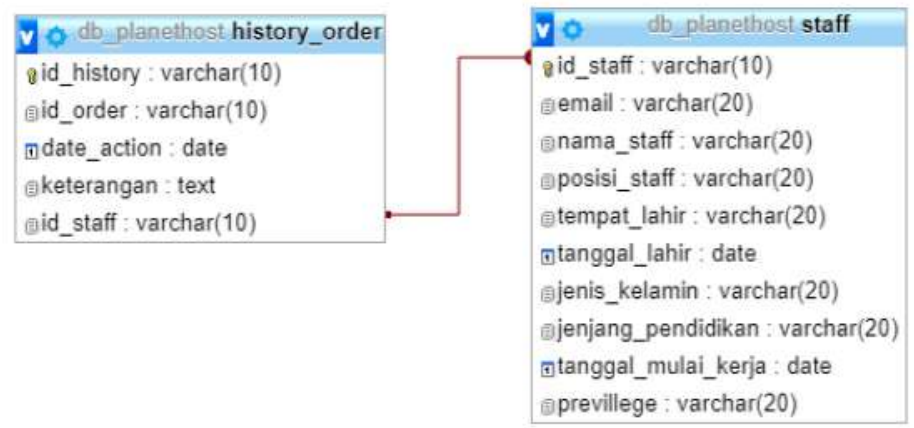

Gambar 5. Skema Basis Data History Order

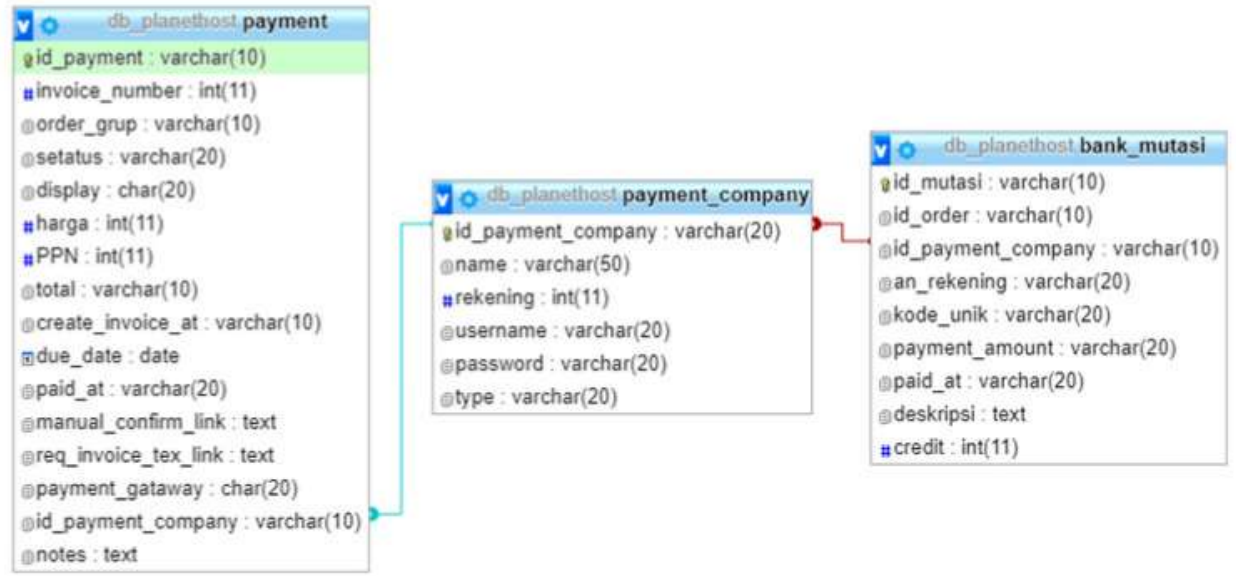

Gambar 6. Skema Basis Data Paymen

Mengacu pada Gambar 3, Gambar 4, Gambar 5, dan Gambar 6 maka bisa dilakukan penulusuran untuk analisa perhitungan ROI guna profitabiltas dari masing-masing produk yang dihasilkan oleh Perusahaan. Tabel yang saling berelasi untuk penelusuran analisa ROI adalah tabel produk, tabel promosi produk dan tabel pesan, ditunjukkan pada Gambar 7. 


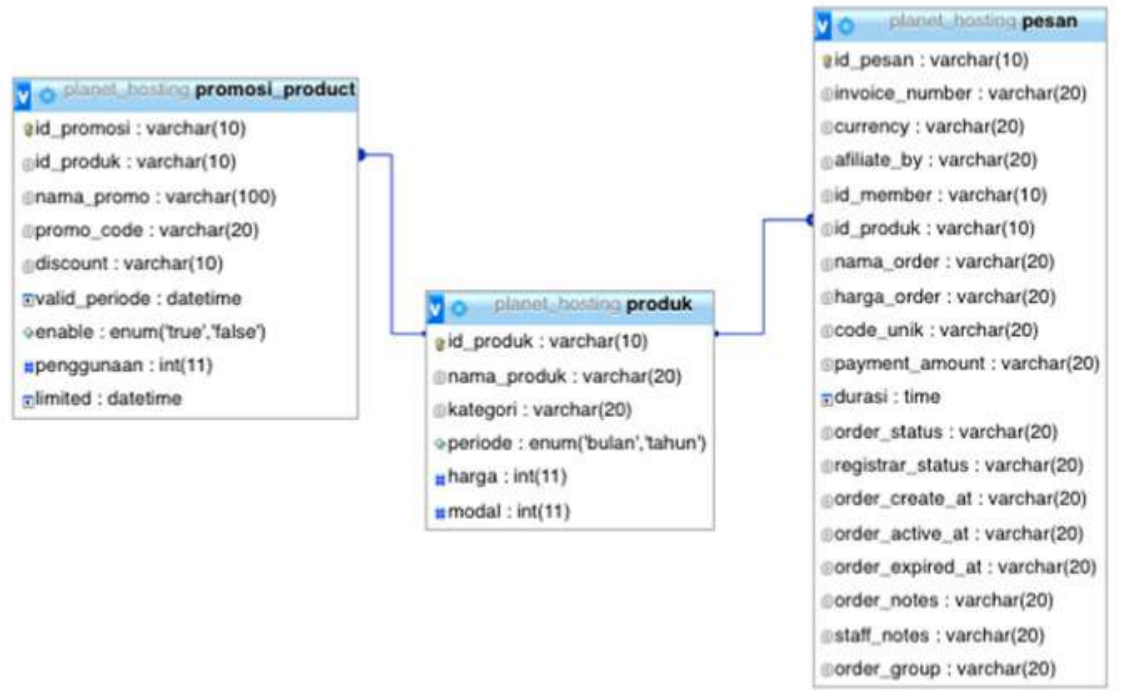

Gambar 7. Skema Database Analisa Perhitungan ROI

Dijelaskan pada Gambar 3, 4, 5, 6 dan 7, tabel yang saling berelasi yang digunakan sebagai penentuan perhitungan promo ROI.

\subsubsection{Tabel Produk}

Tabel produk merupakan tabel yang berisi mengenai produk-produk yang dalam ada dalam pelayanan Planet Web Hosting, dimana tabel produk terelasi dengan tabel promosi_product dan tabel pesan. Keterangan tabel bisa dilihat pada Tabel 2.

Tabel 2. Tabel Produk

\begin{tabular}{|l|l|l|l|l|}
\hline \multicolumn{1}{|c|}{ Field } & \multicolumn{1}{c|}{ Type } & Null & Default & Keterangan \\
\hline id_promosi & varchar (10) & No & None & Primary key \\
\hline id_produk & varchar (10) & No & None & Foreign key \\
\hline promo_code & varchar (20) & No & None & - \\
\hline discount & varchar (10) & No & None & - \\
\hline valid_periode & Datetime & No & None & - \\
\hline enable & enum ('true', 'false') & No & None & - \\
\hline penggunaan & int (11) & No & None & - \\
\hline limite & Datetime & Yes & Null & - \\
\hline
\end{tabular}

\subsubsection{Tabel Promosi Produk}

Tabel promosi produk merupakan tabel yang berisi mengenai data promosi produk yang tersedia. Pada tabel ini untuk menampilkan dan menyimpan hasil promosi yang digunakan untuk potongan diskon sesuai kode promo. Pada atribut id_promosi sebagai primary key, keterangan lain terdapat pada Tabel 3.

Tabel 3. Tabel Promosi Produk

\begin{tabular}{|l|l|l|l|l|}
\hline \multicolumn{1}{|c|}{ Field } & \multicolumn{1}{c|}{ Type } & Null & Default & Keterangan \\
\hline id_promosi & varchar (10) & No & None & Primary key \\
\hline id_produk & varchar (10) & No & None & Foreign key \\
\hline nama_promo & varchar $(100)$ & No & None & - \\
\hline promo_code & varchar (20) & No & None & - \\
\hline
\end{tabular}


Citec Journal, Vol. 5, No. 3, Mei 2018 - Juli 2018

\begin{tabular}{|l|l|l|l|l|}
\hline discount & varchar (10) & No & None & - \\
\hline valid_periode & Datetime & No & None & - \\
\hline enable & enum ('true', 'false') & No & None & - \\
\hline penggunaan & int (11) & No & None & - \\
\hline limite & Datetime & Yes & Null & - \\
\hline
\end{tabular}

\subsubsection{Tabel Pesan}

Tabel pesan menampung data pemesanan dari pembeli hosting dengan id_pesan sebagai primary key dan keterangan lain pada Tabel 4.

Tabel 4. Tabel Pesan

\begin{tabular}{|l|l|l|l|l|}
\hline \multicolumn{1}{|c|}{ Field } & \multicolumn{1}{c|}{ Type } & Null & Default & Keterangan \\
\hline id_pesan & varchar (10) & No & None & Primary Key \\
\hline invoice_number & varchar (20) & No & None & - \\
\hline currency & varchar (10) & No & None & - \\
\hline afiliate_by & varchar (10) & No & None & - \\
\hline id_member & varchar (10) & No & None & - \\
\hline id_produk & varchar (10) & No & None & - \\
\hline nama_order & varchar (20) & No & None & - \\
\hline harga_order & varchar (20) & No & None & - \\
\hline code_unik & varchar (20) & No & None & - \\
\hline payment_amount & varchar (20) & No & None & - \\
\hline Durasi & time & Yes & Null & - \\
\hline promo_code & varchar (20) & No & None & - \\
\hline order_status & varchar (20) & No & None & - \\
\hline registrar_status & varchar (20) & No & None & - \\
\hline order_create_at & varchar (20) & No & None & - \\
\hline order_active_at & varchar (20) & No & None & - \\
\hline order_expired_at & varchar (20) & No & None & - \\
\hline order_notes & varchar (20) & No & None & - \\
\hline staff_notes & varchar (20) & No & None & - \\
\hline
\end{tabular}

\subsection{Penelusuran Query}

Setelah basis data yang dibutuhkan sudah berelasi dan perhitungan ROI sudah didapatkan dengan hasil perhitungan dari rumus, selanjutnya membuat fungsi View, Store Procedure dan Trigger.

CREATE VIEW view_ROI_pesan AS SELECT p.id_pesan, p.invoice_number, p.id_produk, prd.nama_produk, prd.harga, p.durasi, p.periode_durasi, p.promo_code, p.order_active_at from pesan p LEFT JOIN produk prd on p.id_produk = prd.id_produk

Kegunaan fungsi View basis data untuk menampilkan data-data pada tabel pesan yang memiliki keterkaitan dengan kebutuhan analisa ROI. Hal ini dibuat untuk mempermudah dan mempersingkat query join pada saat akan melakukan select data yang dibutuhkan untuk melakukan perhitungan ROI, ditunjukkan pada Gambar 10.

\begin{tabular}{|l|r|r|r|}
\hline promo_code & modal & NPV_Profit & Net_return \\
\hline HARBOLNAS & 3500000 & 7200000 & 3700000 \\
\hline BLKFRDY75 & 3500000 & 4725000 & 1225000 \\
\hline & 0 & 12522000 & 12522000 \\
\hline
\end{tabular}

Gambar 10. Tampilan View Budget, NPV, Profit dengan Query 
Tampilan Menu ROI pada Gambar 11 mengilustrasikan tampilan antar muka untuk admin atau pembuat kebijakan dalam perusahaan mengenai presentasi sesuai dengan nilai laba perusahaan.

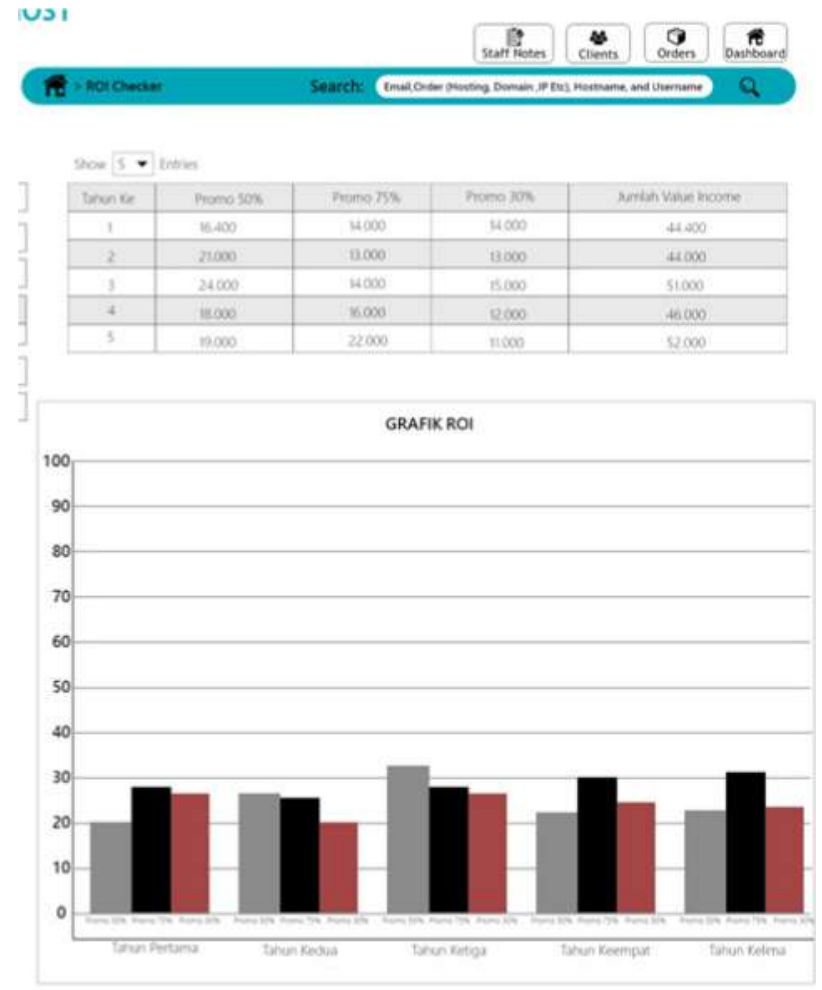

Gambar 11. Tampilan Antar Muka Hasil ROI

Store procedure digunakan untuk membagi beban resource yang terpakai pada saat aplikasi dijalankan. Store procedure juga efektif digunakan untuk eksekusi query yang dilakukan secara rutin yang mana proses dilakukan pada database server sehingga dapat memangkas waktu eksekusi query. Store procedure subtotal_revenue digunakan untuk menampilkan subtotal revenue pembelian suatu produk berdasarkan parameter produk yang di input beserta periodenya.

CREATE PROCEDURE subtotal revenue ( IN kode_produk VARCHAR(10), IN tanggal mulai DATE, IN

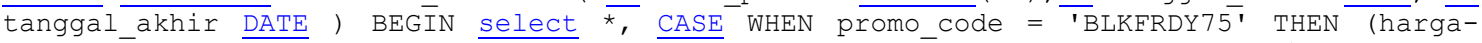
(harga* (SELECT discount from promosi product WHERE promo code = 'BLKFRDY75'))/100)*durasi WHEN promo_code $=$ 'HARBOLNAS' THEN (harga-(harga* (SELEC̄T discount from promosi_product WHERE promo code = 'HARBOLNAS'))/100)*durasi ELSE (harga*durasi) END as subtotal from view roi pesan where id produk= kode produk AND order active at BETWEEN tanggal mulai AND tangōal_akhir;

Trigger merupakan suatu kumpulan query yang digunakan untuk dapat mengeksekusi 1 tabel atau beberapa tabel agar memudahkan dalam otomatisasi data dan perhitungan data [20]. Relasi antar tabel agar terjaga, maka penggunaan trigger digunakan untuk menghitung penjumlahan penggunaan kode promo pada suatu pembelian. Apabila dilakukan insert data pada tabel pesan dengan memasukkan kode promo maka nantinya jumlah penggunaan kode promo pada tabel promosi_produk akan otomatis bertambah sesuai dengan jumlah data penggunaan kode promo yang ditambahkan pada tabel pesan. Trigger pencarian awal penggunaan promo ditunjukkan pada Gmabar 12.

CREATE TRIGGER trigger_penggunaan_promo AFTER INSERT ON pesan FOR EACH ROW UPDATE promosi_product SET penggunaan = penggunaant1 where promo_code $=$ new.promo_code; 


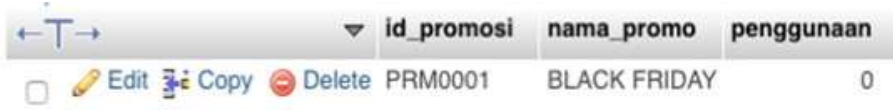

Gambar 12. Tampilan Trigger Pencarian Awal Penggunaan Promo

Maka untuk mempermudah dalam perhitungan penggunaan kode promo yang telah digunakan oleh pelanggan, peneliti menambahkan data pada tabel_pesan. Hal ini dilakukan untuk menguji apakah Trigger yang telah dibuat berjalan dengan baik atau tidak. Insert data dilakukan pada tabel pesan, namun ketika insert data menampilkan notifikasi berhasil dilakukan pengecekan pada tabel promosi_produk pada field penggunaan dan hasilnya jumlah penggunaan yang awalnya 0 bertambah jadi 1 . Sehingga dapat disimpulkan bahwa Trigger yang dibuat sudah dapat berjalan dengan baik. Trigger penambahan data penggunaan promo ditunjukkan pada Gambar 13.

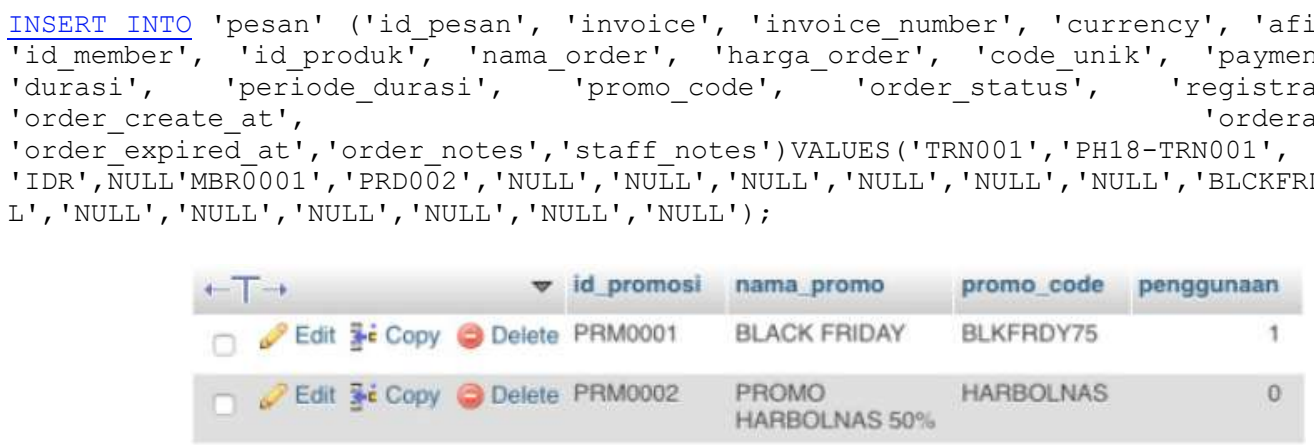

Gambar 13. Tampilan Trigger Penambahan Data Penggunaan Promo

Setelah membuat fungsi View, Store Procedure dan Trigger selanjutnya dilakukan penulusuran query. Penelusuran query ini menggunakan fasilitas beberapa select dan call untuk menampilkan informasi berkenaan dengan transaksi penjualan secara periodik yang terjadi dan menampilkan total revenue perhitungan diskon berdasarkan kode kupon yang ditentukan, seperti ditunjukkan pada Gambar 14.

Select MONTHNAME (order_active_at) as bulan, count (invoice_number) as jumlah_transaksi from view roi pesan where order_active_at BETWEEN '2018-11-01' AND '2018-12-31' GROUP BY $\operatorname{MONT\overline {H}}$ (order_active_at)

\begin{tabular}{lr} 
bulan & jumlah_transaksi \\
\hline November & 31 \\
\hline December & 49
\end{tabular}

Gambar 14. Penelusuran Query Produk Terlaris November

Pada Gambar 15 hasil penelusuran produk webhosting premium dengan kode PRD0002 terdapat 2 buah promo yang berlaku yaitu promo Black Friday dan juga promo Harbolnas. Sisa jumlah lainnya adalah pembelian non promo. select nama_produk, count (id_produk) as total_terjual, SUM(CASE WHEN promo_code=
'BLKFRDY75' THEN 1 ELSE O END) as black friday, SUM (CASE WHEN promo_Code= 'HARBOLNAS' THEN
1 ELSE 0 END) as harbolnas, SUM (CASE WHEN promo_code=' THEN 1 ELSE 0 END) as tanpa_promo
from view_roi_pesan where id_produk='PRD0002' AND order_active_at BETWEEN '2018-11-01' AND
'2018-12-31' GROUP by id_produk

\begin{tabular}{|lrl|l|l}
\hline nama_produk & total_terjual & black_friday & harbolnas & tanpa_promo \\
\hline Web Hosting Premium & 47 & 21 & 16 & 10
\end{tabular}

Gambar 15. Penelusuran Produk Promo \& Tanpa Promo 
Penelusuran pada Gambar 16, dilakukan select semua data pada kode produk dengan pembelian terbanyak dari hasil penelusuran.

\begin{tabular}{|c|c|c|c|c|c|c|c|c|c|}
\hline id pesan & invoice_number & id produk & nama produk & harga & durasi & periode durasi & promo code & order_active at & subtotal \\
\hline TANO032 & PH18-TRNOD18 & PRD0002 & Web Hosting Premium & 25000 & 36 & bulan & BLKFADY75 & $2018-12-03$ & 225000 \\
\hline TANCO33 & PH18-TRNOD19 & PRD0002 & Web Hosting Premium & 25000 & 36 & bulan & BL.KFADY75 & $2018-12-04$ & 225000 \\
\hline TANOO34 & PH18-TANOOZO & PRD0002 & Web Hosting Premium & 25000 & 36 & bulan & BLKFADY75 & $2018-12.05$ & 225000 \\
\hline TANo035 & PH18-TRNO021 & PRD0002 & Web Hosting Premium & 25000 & 36 & bulan & BLKFADYT5 & $2018-12-06$ & 225000 \\
\hline TANDO36 & PH18-TRNOO22 & PRD0002 & Web Hosting Premium : & 25000 & 36 & bulan & BLKFADY75 & $2018-12-07$ & 225000 \\
\hline TAN0037 & PH18-TRNO023 & PRD0002 & Web Hosting Premium & 25000 & 36 & bulan & BL.KFADY75 & $2018-12-08$ & 225000 \\
\hline TANOO38 & PH18-TRNOO24 & PRD0002 & Web Hosting Premium & 25000 & 36 & bulan & BLKFADY75 & $2018-12-08$ & 225000 \\
\hline TRNO039 & PH18-TRN0025 & PRD0002 & Web Hosting Premium & 25000 & 36 & bulan & BLKFADY75 & $2018 \cdot 12-08$ & 225000 \\
\hline TANOO40 & PH18-TRN0026 & PRD0002 & Web Hosting Premium & 25000 & 36 & bulan & BLKFADY75 & $2018-12-08$ & 225000 \\
\hline TANDO44 & PH18-TRN0030 & PRD0002 & Web Hosting Premium & 25000 & 12 & bulan & & $2018-12-08$ & 300000 \\
\hline TANOO45 & PH18-TRNO031 & PRDO002 & Web Hosting Premium & 25000 & 12 & bulan & & $2018-12-08$ & 300000 \\
\hline TAN0046 & PH18-TAN0032 & PRD0002 & Web Hosting Premium & 25000 & 12 & bulan & & $2018-12-08$ & 300000 \\
\hline TAN0047 & PH18-TRNO033 & PRD0002 & Web Hosting Premium & 25000 & 36 & bulan & HARBOLNAS & $2018-12-09$ & 450000 \\
\hline TANoO48 & PH18-TRNO034 & PRD0002 & Web Hosting Premium & 25000 & 36 & bulan & HARBOLNAS & $2018-12-09$ & 450000 \\
\hline TRNOO49 & PH18-TRNOO35 & PRD0002 & Web Hosting Premium & 25000 & 36 & bulan & HARBOLNAS & $2018-12-09$ & 450000 \\
\hline TANOO50 & PH18-TRN0036 & PRD0002 & Web Hosting Premium & 25000 & 36 & bulan & HARBOLNAS & $2018-12-09$ & 450000 \\
\hline TANO051 & PH18-TANO037 & PRD0002 & Web Hosting Premium & 25000 & 36 & bulan & HARBOLNAS & $2018-12-09$ & 450000 \\
\hline TANo052 & PH18-TRNOO38 & PRD0002 & Web Hosting Premium & 25000 & 36 & bulan & HARBOLNAS & $2018-12.09$ & 450000 \\
\hline TANOO53 & PH18-TRNOO39 & PRD0002 & Web Hosting Premium & 25000 & 12 & bulan & & $2018-12-10$ & 300000 \\
\hline TRNo054 & PH18-TRN0040 & PRDDOOR & Web Hosting Premium : & 25000 & 12 & bulan & & $2018-12-11$ & 300000 \\
\hline TAN0055 & PH18-TRNO041 & PRD0002 & Web Hosting Premium & 25000 & 36 & bulan & HARBOLNAS & $2018-12-12$ & 450000 \\
\hline TANO057 & PH18-TRNO043 & PRD0002 & Web Hosting Premium & 25000 & 12 & bulan & & $2018-12-14$ & 300000 \\
\hline
\end{tabular}

\section{Gmbar 16. Penelusuran Total Revenue Perhitungan Diskon}

Penelusuran ini mengacu pada rumus perhitungan ROI, berikut query untuk perhitungan ROI. Hasil eksekusi query digunakan untuk mendapatkan prosentasi ROI keberhasilan suatu promo.

select promo_code, modal, SUM(CASE WHEN promo_code = 'BLKFRDY75' THEN (harga(harga* (SELECT discount from promosi product WHERE promo code = 'BLKFRDY75'))/100)*durasi WHEN promo code = 'HARBOLNAS' THEN (harga-(harga* (SELECT discount from promosi product WHERE promo_code = 'HARBOLNAS'))/100)*durasi ELSE (harga*durasi) END) as NPV_Profit, (SUM(CASE WHEN promo_code $=$ 'BLKFRDY75' THEN (harga-(harga*(SELECT discount from promosi_product WHERE promo_code = 'BLKFRDY75'))/100)*durasi WHEN promo code = 'HARBOLNAS' THEN (harga-(harga*(SELECT discount from promosi_product WHERE promo_code= 'HARBOLNAS'))/100)*durasi ELSE (harga*durasi) END) - modal) as Net return, (((SUM (CASE WHEN promo_code = 'BLKFRDY75' THEN (harga-(harga*(SELECT discount from promosi_product WHERE promo_code $=$ 'BLKFRDY75')/ /100)*durasi WHEN promo_code = 'HARBOLNAS' THEN (harga(harga* (SELECT discount from promosi product WHERE promo code = 'HARBOLNAS'))/100)*durasi ELSE (harga*durasi) END) - moda $\bar{l}) /$ modal)*100) as $\overline{R O I}$ from view_roi_pesan where id_produk='PRD0002' GROUP BY promo_code DESC

\begin{tabular}{lrrrr} 
promo_code & modal & NPV_Profit & Net_return & ROI \\
HARBOLNAS & 3500000 & 5400000 & 1900000 & 54.285714285714285 \\
\hline BLKFRDY75 & 3500000 & 5175000 & 1675000 & 47.85714285714286 \\
\hline & 3500000 & 4800000 & 1300000 & 37.142857142857146
\end{tabular}

Gambar 17. Analisis ROI Dengan Query

Penjelasan pada gambar 17, jika presentasi terbesar adalah promo Harbolnas dengan total 54\%. Promo Hari Belanja Online Nasional (Harbolnas) dengan diskon 54\% lebih menarik perhatian pelanggan dan promo tersebut lebih berhasil. Penelusuran jumlah pembelian periode November - Desember dilakukan dengan penelusuran query berikut (lihat gambar 18). 


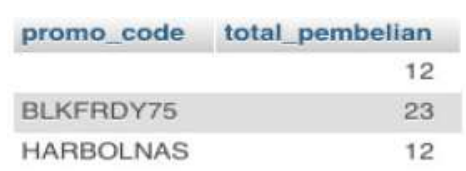

Gambar 18. Hasil Akhir Pembelian Promo dan Non Promo

Hasil penawaran promo Black Friday (diskon $75 \%$ ) jumlah pembelian meningkat dari biasanya, namun untuk keuntungan dan ditinjau dari tingkat keberhasilan promo Hari Belanja Online Nasional atau Harbolnas (diskon 50\%) lebih signifikan berhasil di saat waktu yang bersamaan. Pembelian non promo 12 produk, kode promo Black Friday 23 produk dan kode promo Harbolnas 12 produk.

\section{KESIMPULAN}

Berdasarkan uraian pembahasan dan hasil dari penelusuran query didapatkan kesimpulan sebagai berikut:

1. Perhitungan keberhasilan suatu promo dilakukan dengan melihat hasil penulusuran suatu transaksi pembelian dalam jumlah banyak.

2. View digunakan untuk menampilkan modal suatu produk berdasarkan kode produk, hasilnya akan menampilkan NPV profit dari hasil transaksi pembelian masing-masing promo yang akan di gunakan dalam menhitung ROI.

3. Pembelian dengan kode promo Harbolnas (diskon 50\%) mendapatkan total pembelian 12 produk kemudian kode promo Black Friday (diskon 75\%) total pembelian 23 produk dan pembelian non-promo menghasilkan total pembelian 12 produk.

4. Pembelian dengan berdasarkan total produk tertinggi adalah kode promo Black Friday, namun kode promo Harbolnas lebih signifikan dalam memperoleh laba yaitu 54\% lebih menarik perhatian selama periode November-Desember.

\section{SARAN}

Adapun saran untuk penelitian selanjutnya sebaiknya menelusuri lebih dalam:

1. Faktor-faktor apa yang membuat sebuah promo berhasil.

2. Menelusuri keterkaitan variable lain yang berhubungan dengan promosi misalnya penelusuran siapa yang berhak mendapatkan promo serta faktor apa saja yang menjadi pertimbangan pengambilan keputusan.

3. Menelusuri dengan metode lain atau menggabungkan dengan metode perhitungan lain agar mendapatkan hasil yang lebih akurat dengan membandingkan pada penelitian ini.

\section{DAFTAR PUSTAKA}

[1] Subawa, N. S., Widhiasthini, N. W., 2018, Transformasi Perilaku Konsumen Era Revolusi Industri 4.0, Conference on Management and Behavioral Studies, Jakarta, 25 Oktober.

[2] Ahmed, K., Mehmood, N., 2012, The impact of promotional tools on sales growth (Evidence from Northern Rural Areas in Pakistan), IIJCRB Journal, No. 6, Vol. 4, Hal. 202-216.

[3] Wulandari, A. C., 2012, Analisis Return on Marketing Investment (ROMI) Pada Usaha 13th Shoes, Skripsi, Institut Manajemen TELKOM, Bandung.

[4] Hermawati, D., Paramitha, P. D., Oemar, A., 2018, Pengaruh Return on Investment (Roi) dan Corporate Social Responsibility (Csr) Terhadap Nilai Perusahaan dengan Profitabilitas 
sebagai Variabel Moderating, Jurnal Ilmiah Mahasiswa S1 Akuntansi, Universitas Pandanaran, No.4, Vol. 4, 108-109.

[5] Goldstein, J. H., Pejchar, L., and Daily, G. C., 2008, Using return-on-investment to guide restoration: a case study from Hawaii, Wiley Periodicals, Inc, Vol. 1, Hal. 236-243.

[6] Bismo, Y. A., Mantriwira, D., Sumanto, F., 2017, Analisis Kinerja Optimasi Query Cross Join, Natural Join dan Full Outer Join, CSRID Journal, No. 2, Vol. 9, Hal. 86-95.

[7] Gat, 2015, Perancangan Basis Data dengan Menerapkan Model Data Relasional, Citec Journal, No. 4, Vol.2, Hal. 304-315.

[8] Sepsugiarto, 2011, Datawarehouse Sebagai Alat Penunjang Pengambil Keputusan Bisnis Dalam Analisis Penjualan: Studi Kasus Pada Bagian Penjualan PT. XYZ, ComTech, No. 2, Vol. 2, Hal. 835-848.

[9] Takata, 2017, Database Management System and Database Management Method (Patent Application Publication (10)), Vol. 1, No. 19.

[10] Kusrini, 2007, Strategi Perancangan dan Pengelolaan Basis Data, ANDI OFFSET, Yogyakarta

[11] Nasir Mohamad., 2017, Forum Ekonomi dan Sosial Ke-1 2017 Ikatan Sarjana Ekonomi Indonesia Cabang Semarang, Seminar Ketahanan Pangan dan Pengentasan Kemiskinan.

[12] Basri, H., Nurmalasari, Jaelani, M., 2018, Web Progresif Sistem Informasi Pelelangan Produk Online pada PT Nusantara Sarana Outlet Jakarta, Jurnal Piksel, No. 1, Vol. 6, Hal. 21-28

[13] Utami, A. A., and Saraswati, T. G., 2018, Analisis Model Bisnis Start Up Web Hosting Di Kota Bandung Menggunakan Bussines Model Canvas (Studi Kasus Pada Qwords.com), eProceeding of Management, No. 2, Vol. 5, Hal. 2538-2546.

[14] Arief, M. R., 2006, Pemrograman Basis Data Menggunakan Transact-SQL dengan Microsoft SQL Server 2000. Yogyakarta: Andi Publisher.

[15] Widodo, A. W., Kurnianingtyas. D., 2017, Sistem Basis Data. UB Press, Malang.

[16] Bedoya, H., Cruz, F., Lema, D., Singkorapoom, S., 2016, External Procedures, Triggers, and User-Defined Function on DB2 for I, IBM Redbooks, Indianapolis.

[17] Rangkuti, F., 2009, Mengukur Efektivitas Program Promosi \& Analisis Kasus Menggunakan SPSS, Gramedia Pustaka Utama, Jakarta.

[18] Bustomi, Z., Hidayat, R. R., Sulasmiyati, S., 2015., Analisis Capital Budgeting Untuk Menilai Kelayakan Rencana Investasi Aktiva Tetap (Studi Kasus Pada PT. Citra Perdana Kendedes Malang Periode 2012-2014), Jurnal Administrasi Bisnis, No. 1, Vol. 45, Hal. 6369.

[19] CFI Education Inc, What is Return on Investmen?, Corporate Finance Institute, 2018, https://corporatefinanceinstitute.com/resources/knowledge/finance/return-on-investmentroi-formula/, diakses tanggal 28 Desember 2018.

[20] Azis, A., 2017, Trik Bermain Sql Server 2005 dengan Trigger, Procedure, dan View, Pendidikan Deepublish, Yogyakarta. 